\title{
Study on Corporate Environmental Performance Evaluation Based on Improved DEA
}

\author{
Liu Ming \\ School of Economics and Management, Weifang University, Weifang, Shandong, China (wfuliuming@ 126.com)
}

\begin{abstract}
With the increasingly serious of environmental problems, the government and enterprises has paid more and more attention to corporate environmental performance. It is urgent to construct scientific environmental performance evaluation system and method. Based on the practice of enterprises in china, with reference to ISO14031 and evaluation of ecological benefit, the corporate environmental performance evaluation index system was build in the paper. In order to improve the operability of evaluating, the DEA model was improved. The study will make the environmental performance evaluation of china more scientific and standardized, and guide for the government's environmental management policy and corporate environmental strategy.
\end{abstract}

Keywords - corporate environmental performance, evaluation index system, DEA

\section{基于改进 DEA 的企业环境绩效评价研究}

\author{
刘 明 \\ 潍坊学院经济管理学院, 潍坊, 山东, 中国
}

摘 要 环境问题的日益突出, 使得政府和企业自身越来越重视企业生产的环境绩效, 急需构建科学可行的环境绩效评价体系和 方法。本文基于我国企业的实际，借鉴国际 ISO14031 评价标准和生态效益评价标准，建立了与国际接轨的、适合我国的企业环境绩 效评价指标体系, 并通过对 DEA 模型进行改进, 给出了具有可操作性的综合评价方法。本文的研究, 将有助于我国企业环境绩效评 价工作实现科学化和规范化，对政府环境管理政策和企业环境策略的制定起到理论和现实指导作用。

关键词＼cjkstart企业环境绩效，评价指标体系，DEA

\section{1. 引言}

随着我国经济的快速发展，环境问题也日益突出地显 现出来, 已经成为政府和社会各界所关注的重要问题之一。 不仅仅是政府, 企业也已经意识到环境因素己成为影响其 经济活动的重要因素, 越来越重视企业的环境绩效评价。 构建科学的企业环境绩效评价体系迫在眉睫。然而, 现有 的企业绩效评价体系缺乏对企业环境绩效的系统设计, 企 业为环境保护而做出的努力和贡献难以充分体现。

基于此, 本文借鉴国际 ISO14031 评价标准和生态效益 评价标准, 结合我国企业实际, 构建与国际接轨的、适合 我国国情的企业环境绩效评价指标体系, 并通过改进 DEA 评价方法实现对企业环境绩效的科学评价。

潍坊学院博士科研基金支持（资助号：2013BS22）

\section{2. 企业环境绩效评价指标体系的构建}

企业环境绩效评价指标体系是由众多评价指标组成的 指标系统, 共同形成对企业环境绩效的完整刻画, 科学评 价企业环境管理所达到的水平和效果。构建科学合理的评 价指标体系是企业环境绩效评价的基础。

\section{1 代表性的企业环境绩效评价指标体系}

国外关于对于企业环境战略绩效评价指标及标准的系 统性研究始于 20 世纪 90 年代。许多学者和机构发布了可 供企业应用参考的环境绩效评价标准。其中, 以国际标准 化组织制定的 ISO14031 环境绩效评价标准和世界永续发 展委员会制定的以生态效益为核心的环境绩效评估标准最 为代表。另外, 我国国家环保总局也于 2003 年发布了环境 绩效评级系统，并沿用至今。 
(1) ISO14031 国际环境绩效评价标准

国际标准化组织自 1994 年后陆续制定了一些有关环 境绩效评价的国际标准。该组织于 1999 年 11 月 15 日提供 了规范化依据——ISO14031 (企业环境绩效评价标准)。

在 ISO14031 所规定的环境指标, 依其评估对象和目的的范 畴大小, 分为环境状态指标和环境绩效指标, 而环境绩效 指标又可分为管理绩效指标及作业绩效指标, 可分别针对 组织外界环境, 组织本身操作系统及管理系统进行评估。

(2) 生态效益评价标准

世界可持续发展委员会 (WBCSD) 于 2000 年 8 月提 出了全球第一套生态效益评价标准。生态效益是从生态平 衡的角度来衡量效益, 以期达到企业经济绩效与环境绩效 共赢的局面。生态效益指标可表示为:

生态效益=产品或服务的价值/环境的影响

产品或服务的价值跟经济效益有关, 如产能、产量、 总营业额等, 环境的影响与环境效益有关, 如资源消耗总 量、每单位产品的废水排放量、温室效应气体排放总量等。 这个指标要求在降低资源使用和对环境影响的同时实现产 品或服务价值最大化。

（3）国家环保总局发布的环境绩效评级系统

国家环境保护总局 2003 年发布了《关于开展创建国家 环境友好企业活动的通知》。该通知主要以排污是否达标为 准, 把企业的环境行为结果分为很好、好、一般、差、很
差五个等级, 并依次以绿色、蓝色、黄色、红色、黑色表 示, 详细分类见表 1 。

表 1 国家环保总局公布的环境绩效评级系统

\begin{tabular}{|c|c|l|}
\hline $\begin{array}{c}\text { 环境行 } \\
\text { 为等级 }\end{array}$ & 含义 & 环境行为等级说明 \\
\hline $\begin{array}{c}\text { 绿色 } \\
\text { (很好) }\end{array}$ & 优秀 & $\begin{array}{l}\text { 企业达到国家排放标准, 通过清洁生产 } \\
\text { 审核, 严格遵守环境法律法规, 环境行 } \\
\text { 表现突出。 }\end{array}$ \\
\hline $\begin{array}{c}\text { 蓝色 } \\
\text { (好 })\end{array}$ & 守法 & 企业达到国家排放标准, 没有违法行为。 \\
\hline $\begin{array}{c}\text { 黄色 } \\
\text { (一般 })\end{array}$ & 基本达标 & $\begin{array}{l}\text { 企业总体达到国家排放标准, 个别指标 } \\
\text { 超标。 }\end{array}$ \\
\hline $\begin{array}{c}\text { 红色 } \\
\text { (差) }\end{array}$ & 违法 & $\begin{array}{l}\text { 企业排放超标, 有较严重的环境污染行 } \\
\text { 为。 }\end{array}$ \\
\hline $\begin{array}{c}\text { 黑色 } \\
(\text { 很差) }\end{array}$ & 严重违法 & 企业排放严重超标, 有重大违法行为。 \\
\hline
\end{tabular}

\section{2 企业环境绩效评价指标体系构建}

参考上述国内外通行的环境绩效评价体系, 结合我国 环保总局的评价体系, 根据客观全面、定量指标与定性指 标相结合、财务指标与非财务指标相结合的原则, 本文构 建如下三级评价指标体系，如表 2 所示。

表 2 企业环境绩效评价指标体系

\begin{tabular}{|c|c|c|}
\hline 一级指标 & 二级指标 & 三级指标 \\
\hline \multirow{3}{*}{ 环保法规达标类指标 } & 达到排放标准 & 有排污许可, 达到国家各项排放标准, 遵守各项环保法规。 \\
\hline & 清洁生产审核 & 通过清洁生产强制性审核。 \\
\hline & 通过环评 & 新改扩建项目环保手续齐全, 落实三同时。 \\
\hline \multirow{3}{*}{ 投入类指标 $X_{j}$} & 环保投入 & $\begin{array}{l}\text { 1.废弃物处理相关费用 } \\
\text { 2.环境管理训练相关费用 }\end{array}$ \\
\hline & 资源投入 & $\begin{array}{l}\text { 1.单位产值能源用量 } \\
\text { 2.单位产值用水量 } \\
\text { 3.单位产值用电量 }\end{array}$ \\
\hline & 环境损害 & $\begin{array}{l}\text { 1.单位产值工业废水排放量 } \\
\text { 2.单位产值工业废气排放量 } \\
\text { 3.单位产值固体废物产生量 }\end{array}$ \\
\hline \multirow[t]{2}{*}{ 产出类指标 $Y_{j}$} & 环境收益 & $\begin{array}{l}\text { 1.能源节省率 } \\
\text { 2.工业废水综合利用率 } \\
\text { 3.工业废气综合利用率 } \\
\text { 4.工业固体废物综合利用率 }\end{array}$ \\
\hline & 财务收益 & $\begin{array}{l}\text { 1.净资产收益率 } \\
\text { 2.流动比率 } \\
\text { 3.销售净利润 }\end{array}$ \\
\hline
\end{tabular}


企业环境绩效评价的一级指标包括三类:

（1）环保达标类指标。主要量化企业生产中对环保法

规的遵守情况, 主要包括是否通过清洁生产强制性审 核、新改扩建项目环评手续齐全、排污达到排放标准, 以 及落实 “三同时” (建设项目的环境保护设施与主体工程同 时设计, 同时施工, 同时投入使用)。该指标是企业环境管 理的最基本目标, 如果企业环境违法, 则无需进一步评价 其环境绩效。

（2）投入类指标。投入类指标主要包括企业的环保投 入和资源投入。环保投入包括企业废弃物处理相关的设备 设施购置保养运转费用、环境管理培训执行的费用等。资 源投入指每生产单位产品投入的能源、水、电的用量。

环境损害是指企业生产对环境产生的不利影响, 本属 产出类指标。但在指标使用时, 希望环境损害越小越好, 其性质与投入类指标类似，所以将其视作投入类指标。

(3) 产出类指标。产出类指标主要包括环境收益和经 济收集。环境收益指企业采取环境管理后得到的收益, 主 要包括能源节省率和三废综合利用率。财务收益主要评价 企业的生产经营业绩, 主要包括净资产收益率、流动比率、 销售净利润。

\section{3. 评价程序设计}

根据文构建的企业环境绩效评价指标体系, 结合各个 评价方法的特点, 本文选用 DEA 法进行评价。评价程序分 为两步, 如图 3 所示。

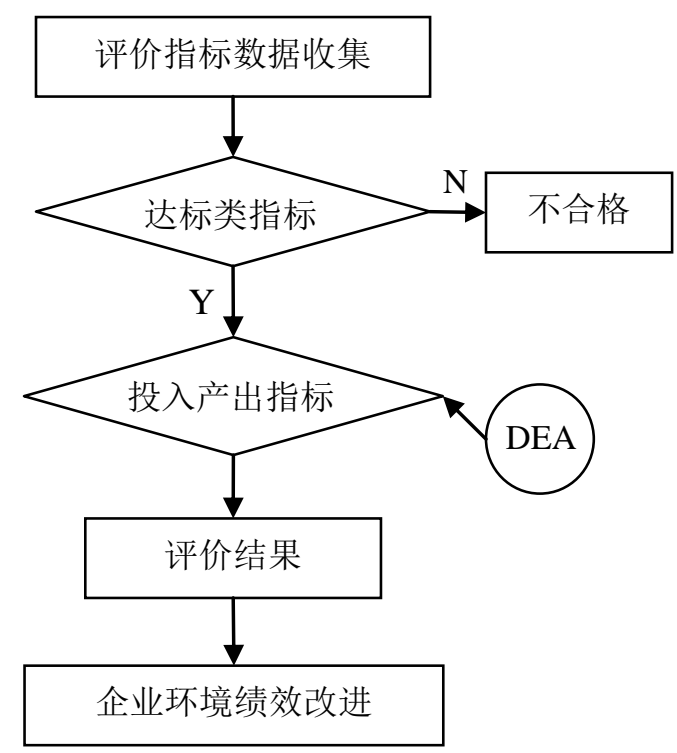

图 3 综合评价程序

首先, 根据达标类指标对企业环境法规遵守情况进行 评价, 达标的进入第二步, 否则为不合格。
其次, 运用 DEA, 根据企业投入类指标和产出类指标 进行企业环境绩效评价, 并根据评价结果对企业环境绩效 进行改进。

\section{4. 企业环境绩效评价的改进 DEA 法}

\subsection{DEA 基本模型}

数据包络分析法是以相对效率概念为基础发展起来的 一种新的效率评价方法, 是处理多目标决策的有效方法。 根据一组输入和输出数据来评价决策单元的优劣, 即评价 各单位的相对效率。

设 $x_{i j}$ 和 $y_{r j}$ 为已知数据, 可以根据历史资料得到; $v_{j}$ 和 $\mu_{r}$ 为变量, 对应于权系数 $V=\left(v_{1}, v_{2}, \cdots, v_{m}\right)^{\mathrm{T}}, U=\left(u, u_{2}, \cdots, u_{m}\right)^{\mathrm{T}}$ 。 在企业环境绩效评价中, 将待评价的企业作为决策单元, 设一共有 $n$ 个企业, 每个企业都有 $m$ 种类型的输入 $(x)$ 和 $s$ 种类型的输出 $(y)$, 定义式 (1) 为企业 $j$ 的效率评价指 数:

$$
h_{j}=\frac{\sum_{r=1}^{n} u_{r} y_{r j}}{\sum_{i=1}^{m} v_{i} x_{i j}} \quad(j=1,2, \cdots, n)
$$

式中:

$x_{i j}-\mathrm{DMU}_{j}$ 对第 $i$ 种输入的投入量, $x_{i j}>0$;

$y_{r j}-\mathrm{DMU} j$ 对第 $\boldsymbol{r}$ 种输出的产出量, $y_{r j}>0$;

$v_{i}$ 一对第 $i$ 类型的输入的一种度量(或称 “权”);

$u_{r}$ 一第 $r$ 种类型输出的一种度量(或称 “权” );

$j=1,2, \cdots, n ; i=1,2, \cdots, m ; \quad r=1,2, \cdots, s$ 。

每个决策单元都有相应的效率评价指数, 而且总可以 适当的选取 $V$ 和 $U$, 使其满足 $h_{j} \leqslant 1, \mathrm{j}=1,2, \cdots, n$ 。

现在对第 $j_{0}$ 个决策单元进行相对有效性评价, 以所有 决策单元的效率评价指数小于等于 1 为约束, 构成如下最 优化 $\mathrm{C}^{2} \mathrm{R}$ 模型:

$$
\begin{aligned}
& \max \frac{U^{\mathrm{T}} Y_{j_{0}}}{V^{\mathrm{T}} X_{j_{0}}} \\
& \left\{\begin{array}{l}
\frac{U^{\mathrm{T}} Y_{j}}{V^{\mathrm{T}} X_{j}} \leq 1 \quad j=1 \cdot, \cdot 2 n, \\
V \geq 0, U \geq 0
\end{array}\right.
\end{aligned}
$$

\section{2 引入虚拟环境绩效最优企业的 DEA 改进模型}

企业环境绩效评价的目的是根据评价结果对各个企业 的优劣进行排序。但是由于传统 DEA 模型权重变化过于灵 活, 容易造成 DMU 有效数量过多的情况, 进而难以实现 
对企业的排序。为解决该问题, 本文借用通过引入虚拟环 境绩效最优企业对 DEA 模型进行改进。

（1）虚拟环境绩效最优企业的构造

在 DEA 投入产出图基础上, 构造第 $n+1$ 个理想决策单 元。令虚拟环境绩效最有企业 $n+1$ 的投入、产出指标数据 分别为:

$$
\begin{gathered}
X_{n+1}=\left(x_{1(n+1)}, x_{2(n+1)}, \cdots, x_{m(n+1)}\right)^{T} \\
Y_{n+1}=\left(\mathrm{y}_{1(n+1)}, y_{2(n+1)}, \cdots, y_{s(n+1)}\right)^{T}
\end{gathered}
$$

且满足:

$$
\begin{aligned}
& x_{i(n+1)}=\min \left(x_{i 1}, x_{i 2}, \cdots, x_{i n}\right), i=1,2, \cdots, m ; \\
& y_{r(n+1)}=\max \left(y_{r l}, y_{\mathrm{r} 2}, \cdots, y_{r s}\right), r=1,2, \cdots, s 。
\end{aligned}
$$

(2) DEA 模型的改进

因第 $n+1$ 个决策单元在所有决策单元中投入最小, 产 出最大, 按照效率评价的定义可知, $\mathrm{DMU}_{n+1}$ 在 $n+1$ 个决策 单元中是最优的, 即是分布于生产前沿面的有效决策单元。 以其效率最大为目标构建评价模型, 则式 (2) 变为:

$$
\begin{aligned}
& \max \frac{U^{\mathrm{T}} Y_{n+1}}{V^{\mathrm{T}} X_{n+1}} \\
& \left\{\begin{array}{l}
\frac{U^{\mathrm{T}} Y_{j}}{V^{\mathrm{T}} X_{j}} \leq 1 \quad j=1,2, \cdots, n+1 \\
V \geq 0, \quad U \geq 0
\end{array}\right.
\end{aligned}
$$

鉴于虚拟环境绩效最优企业的引入, 改进 DEA 模型避 免了大量 DMU 同时有效的情形, 实现了企业的全排序, 更适用于企业环境绩效的评价, 更有利于为政府决策部门 提供参考。

\section{5. 结论}

科学的评价企业的环境绩效, 充分体现企业为环境保 护而做出的 “努力” 和 “贡献”, 一方面, 可以帮助政府准 确评价企业的环境绩效, 加强企业参与环境管理的积极性, 将环境因素纳入其战略管理和经营决策中去; 另一方面, 企业可以通过环境绩效评价发些自身的环境问题进而改 进, 实现可持续发展。
本文借鉴国内外通行的环境绩效评价指标, 结合我国 实际, 建立了企业环境绩效评价指标体系, 并选用改进的 DEA 评价方法进行评价, 使得政府和企业能够科学规范的 评价企业的环境绩效, 对各级政府、行业制定相应环境政 策法规以及企业制定相应策略具有一定的指导意义。

\section{参考文献(References)}

[1] Chen Hao and Xue Shengjia, "The multilevel fuzzy comprehensible evaluation of corporate environmental management performance", Science and Technology Management Research, no.4, pp.56-59, 2006.

[2] Gui Ping and Wang Yi, "Research on corporate environmental performance evaluation index system based on the theory of ecological", Communication of Finance and Accounting, no.8. pp.22-23, 2011.

[3] Song Yijun, Construct and practice of enterprise environment performance index system, Lan Zhou: North China University of Technology, 2007.

[4] Sha Na, The study on enterprise environmental strategy and its environmental performance evaluation, Qing Dao: Ocean University of China, 2012.

[5] Liu Ming, Study on the core manufacture's supplier selection and coordination strategy in green supply chain, Cheng Du: South West Jiaotong University, 2010.

[6] Li Yuming, "Enterprise environmental performance evaluation system research and enlightenment", Friends of Accounting, no.2, pp.22-24, 2010.

[7] Liu Ming, "Construction of supplier selection criterion system of green supply chain based on information gain analysis", Manufacture Engineering, Quality and Production System III, 2014.

[8] UK Department for Environment Food and Rural Affairs. TRUCOST. Environmental Key Performance Indication: Reporting Guidelines for UK Business, 2005

[9] World Business Council of Sustainable Development. Measuring Eco-efficiency: A Guide to Reporting Company Performance, 2000

[10] Liu Limin. Yang Shu-e and Yuan Zhenxing, "Summaty of the international environmental performance evaluation criteria", Statistics and Decision, no.8, pp, 150-153, 2007. 